\title{
Anodic Stripping Voltammetric Determination of Nitrite Using Carbon Paste Electrode Modified with Chitosan
}

\author{
Ibrahim H. I. Habib \\ Microanalytical Chemistry Lab, Applied Organic Chemistry Department, National Research Centre, Cairo, Egypt \\ E-mail: ihihabib@yahoo.com \\ Received December 2, 2010; revised March 7, 2011; accepted May 14, 2011
}

\begin{abstract}
A simple method for anodic stripping voltammetric determination of nitrite using carbon paste electrode modified with biomolecular chitosan, is described. In this method, the electrode is activated electrochemically by scanning 5 replicates over the potential range from +500 to $+1400 \mathrm{mV}$ immersing in $0.5 \mathrm{M} \mathrm{HCl}$ solution. Following this step, the nitrite sample containing $0.1 \mathrm{M} \mathrm{KCl}$ is pre-concentrated on the activated electrode at $+500 \mathrm{mV}$ for $30 \mathrm{~s}$. The deposited anions are then oxidized by different modes of sweep in the oxidation direction. Chemical and electrical parameters affecting the voltammetric measurements are optimized. The peak current is linear proportional to the $\mathrm{NO}_{2}^{-}$concentration within the range $0.41-4.1 \mu \mathrm{g} / \mathrm{ml}$, with detection limit $0.187 \mu \mathrm{g} / \mathrm{m}$ using differential pulse mode. The relative standard deviation is $0.285 \%$ for 2.46 $\mu \mathrm{g} / \mathrm{ml}$ (five replicates). No interference is observed due to oxygen dissolved in the sample so that nitrogen purging is not needed in this case. The result obtained by the modified electrode is more accurate and selective than the unmodified electrode.
\end{abstract}

Keywords: Chitosan, Carbon Paste Electrode, Nitrite, Anodic Stripping Voltammetry

\section{Introduction}

Nitrite is one of the pollutants widely found in natural waters, wastes from fertilizers or intentional additions of nitrites for corrosion control or protection of meat products. Nitrite ions can interact with amines to form nitrosamines which are known as carcinogenic substances. They also may react with hemoglobin and reduce the oxygen carrying capacity of it $[1,2]$. Thus, its concentration in various types of samples has to be controlled by sensitive methods.

The most commonly used method for nitrite determination ranging from trace to ultra trace levels is the electrochemical techniques. This includes polarography [3-7], amperimetry [8,9] and voltammetry [10-14]. The sensitivity can be further enhanced if the surface of bare electrodes is modified chemically with active thin film offering significant advantageous for design and development of electrochemical sensors. According to the literature survey, all electrodes modified by complexes of iron [15,16], palladium [17], iridium [18], cobalt [19], copper [20], mercury [21], cetyltrimethylammonium bromide [10], phosphomolybdic $[22,23]$ or silicotungestic acids
$[24,25]$ have been used successfully for electrochemical oxidation of nitrite. Boron-doped diamond electrode [26] has also been applied for monitoring nitrite, but it needs special instruments not ever available elsewhere.

Chitosan, on the other hand, is natural product extracted from the shell of shrimps, crabs and insects [27]. Because of its ability to bind strongly with many metals [28], chitosan and its derivatives have been applied for electrochemical determination of silver [29,30], platinum [30], palladium [30], gold [30,31], lead [32,33] and iron [34]. In the present work, carbon paste electrode modified with natural chitosan represents the simplest and reproducible analytical tool to determine nitrite in samples.

\section{Experimental}

\subsection{Apparatus and Reagents}

A Metrohm model 693 VA processor and 694 VA stand equipped with a $\mathrm{Ag} / \mathrm{AgCl}-3 \mathrm{M} \mathrm{KCl}$ and a platinum counter electrode are employed. The modified carbon paste electrode is used as the working electrode and prepared as described below. 


\subsection{Preparation of the Modified Carbon Paste Electrode}

The carbon paste is prepared by mixing $175 \mathrm{mg}$ paraffin oil (Fluka), $250 \mathrm{mg}$ synthetic carbon powder 1 - 2 micron (Aldrich) and $48 \mathrm{mg}$ low-viscous Chitosan (Fluka) in agate mortar. The electrode is consisted of stainless steel tube with i.d. $2.5 \mathrm{~mm}$ and $30 \mathrm{~mm}$ deep, moving through it an inner screwed stainless steel connector. The tube is coated externally with Teflon. The tube is packed with the modified carbon paste, compressed with inner screw and smoothed on a wetted Whatman filter paper.

\subsection{Procedure}

The fresh surface electrode is first immersed in $0.5 \mathrm{M}$ $\mathrm{HCl}$ solution and electrically activated by direct current sweep five replicates from +500 to $+1400 \mathrm{mV}$ with scan rate $50 \mathrm{mV} / \mathrm{s}$. The solution is then exchanged by $10 \mathrm{ml}$ of $0.1 \mathrm{M} \mathrm{KCl}$ solution containing $0.41-4.1 \mu \mathrm{g}$ of nitrite and pre-concentrated for $30 \mathrm{~s}$ at $+500 \mathrm{mV}$ with stirring at $2000 \mathrm{rpm}$. After resting for $10 \mathrm{~s}$, one of electrical modes (direct current tast DC, differential pulse DP, square wave SW or first-harmonic alternating current $\mathrm{AC} 1$ ) is ramped from +500 to $+1400 \mathrm{mV}$ with scan rate $50 \mathrm{mV} / \mathrm{s}$, pulse amplitude $50 \mathrm{mV}$, pulse duration $20 \mathrm{~ms}$, measurement time $10 \mathrm{~ms}$, frequency $30 \mathrm{~Hz}$ for SW and $\mathrm{AC} 1$. The experiment is triplicated without electrode re- generation and two standard solutions of nitrite are added sequentially. Average of current peaks due to the sample and standard solutions are taken. For new electrode, the experiment is repeated with new activation of electrode as described before.

\section{Results and Discussion}

Preliminary experiments are carried out to optimize the sensor composition. The height of peak current obtained for nitrite is used to compare the performance of the different chemical and physical parameters. Each parameter is analyzed triplicate with the same sensor and the corresponding average value of peak height is plotted. The working electrode containing 40\% (w/w) water-immiscible organic binders (pasting liquids), viz. paraffin or silicon oils, with/without $4 \%$ chitosan are prepared and examined under identical conditions, i.e. immersing in $0.5 \mathrm{M} \mathrm{HCl}$ prior accumulation and differential pulse stripping voltammetric measurements of nitrite in $0.1 \mathrm{M}$ $\mathrm{KCl}$ solution. It is obvious from Figure 1, the $40 \%$ paraffin oil with $4 \%$ chitosan accumulates afforded highest stripping peak at potential of about $+900 \mathrm{mV}$. Thus, the modifier enhances the sensitivity of the electrode twice more than using paraffinic bare CPE. This enhancement

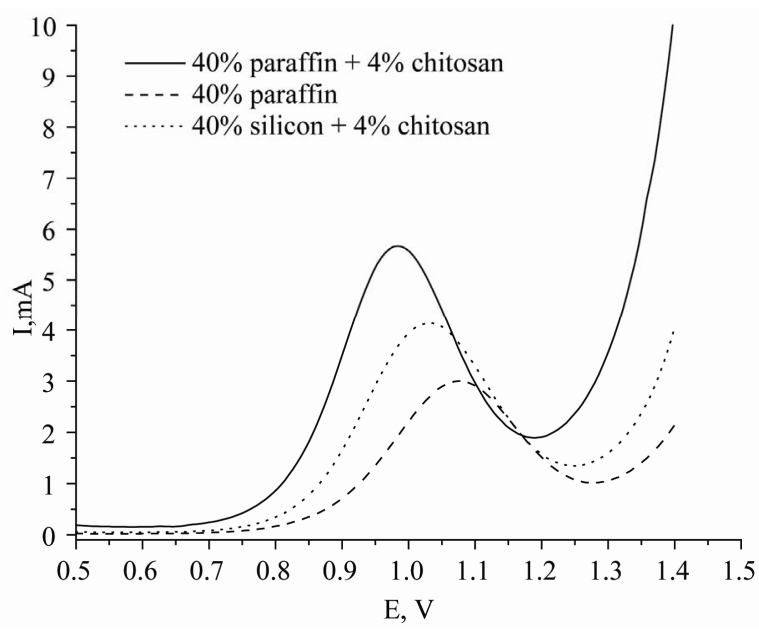

Figure 1. Differential pulse DP cathodic stripping voltammograms for determining nitrite in absence and presence of chitosan with scan rate $60 \mathrm{mV} / \mathrm{s}$, pulse amplitude $50 \mathrm{mV}$ in $0.3 \mathrm{M}$ KCl.

could be explained by the fact that the $-\mathrm{NH}_{2}$ group is converted into $-\mathrm{NH}_{3}^{+}$making it easy to increase the electrostatic attraction of negatively charged nitrite ions on its surface in a similar manner for determining negatively charged palladium, platinum $^{30}$ and lead ${ }^{32}$ chloride complexes

The sensitivity and linear responses towards the nitrite concentrations can also be enhanced by increasing the proportion of chitosan up to $10 \%(\mathrm{w} / \mathrm{w})$ chitosan. Beyond this proportion a depression in the sensitivity is observed as shown in Figure 2.

On the other hand, the influence of $\mathrm{HCl}$ and $\mathrm{KCl}$, separately or in mixture solutions, revealed that in acidic solutions ( $\mathrm{pH}<3.3)$ nitrite is escaped as NO gas and lost

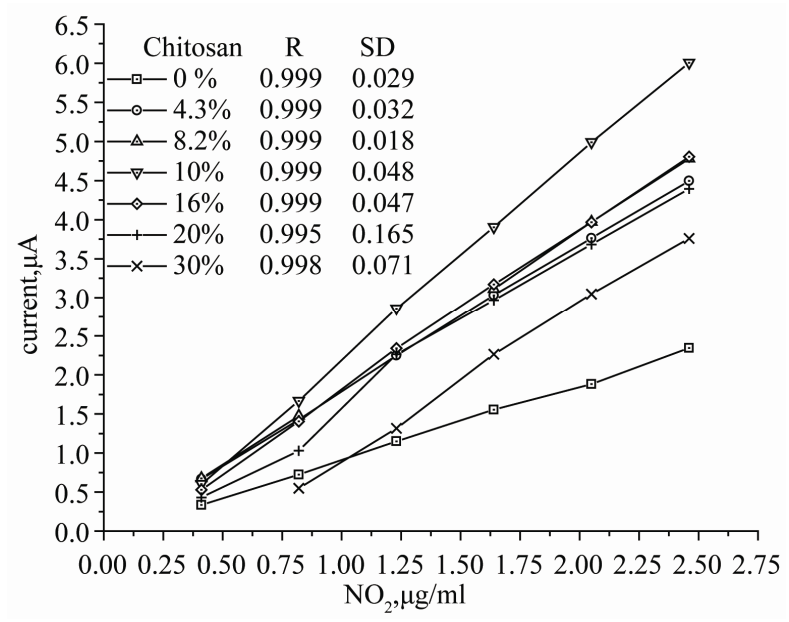

Figure 2. Effect of chitosan (\%, w/w) on the stripping current at different concentrations of nitrite $(0.41-2.46 \mu \mathrm{g} / \mathrm{mol}$ $\mathrm{NO}_{2}$ ) using DP mode with scan rate $60 \mathrm{mV} / \mathrm{s}$, pulse amplitude $50 \mathrm{mV}$ in $0.3 \mathrm{M} \mathrm{KCl}$. 
more when nitrogen gas is bubbled giving up weak peak current. In a neutral medium, $\mathrm{pH}>3.3$, nitrite anion is predominated promoting to strong peak current. Thus, in order to avoid NO gas formation, two separating solutions on two sequential steps are achieved, $0.5 \mathrm{M} \mathrm{HCl}$ solution for the protonation of chitosan followed by 0.1 $\mathrm{M} \mathrm{KCl}$ solution for applying as a neutral supporting electrolyte medium. The latter effect is as depicted in Figure 3 where the concentration of $0.1 \mathrm{M} \mathrm{KCl}$ gives the highest peak current and best linear relation.

The variation of scan rate from 10 to $120 \mathrm{mV} / \mathrm{s}$ revealed that the diffusion current is related linearly with square root of scan rate, but the oxidation reaction proceeded irreversibly as the peak potential shifted linearly to more positive potential with increasing the scan rate. No reduction peak is observed on the reverse scan within the studied potential range indicating that the overall process is chemically irreversible in agreement with the previous reports for nitrite oxidation at different types of electrodes [35,36].

Modulating the direct current tast ramp DCT with various wave forms by using superimposed differential pulse DP, square-wave SW or first harmonic a.c. modulation $\mathrm{AC}$ also studied to explore which one of modes will enhance the sensitivity.

As shown in Figures $\mathbf{4}$ and 5, variation of current with concentration of nitrite ions showed a linear behavior between 0.41 and $4.1 \mu \mathrm{g} / \mathrm{mol}$ of nitrite with correlation coefficients $0.994,0.999,0.998$ and 0.998 for different modes of sweep DC, DP, SW and AC1, respectively. The detection limit based on "three standard deviations of the blank $3 \mathrm{~s}_{\mathrm{B}}$ method [37] is found to be in turn, 0.281, $0.187,0.207$ and $0.241 \mu \mathrm{g} / \mathrm{ml}$ nitrite. The analytical parameters for nitrite determination are reported in Table 1.

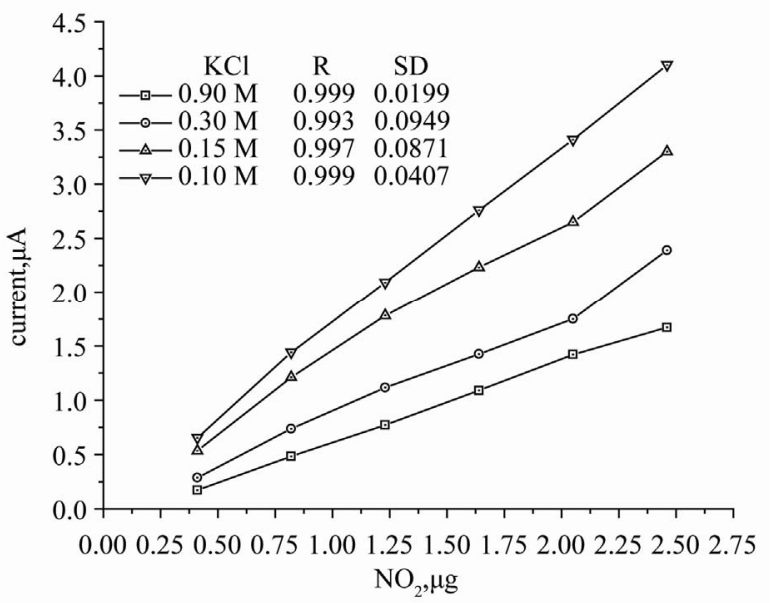

Figure 3. Effect of $\mathrm{KCl}$ on the stripping current at different concentrations of nitrite $\left(0.41-2.46 \mu \mathrm{g} / \mathrm{ml} \mathrm{NO}_{2}\right)$ using $10 \%$ chitosan carbon paste electrode and DP mode with scan rate $60 \mathrm{mV} / \mathrm{s}$ and pulse amplitude $50 \mathrm{mV}$.

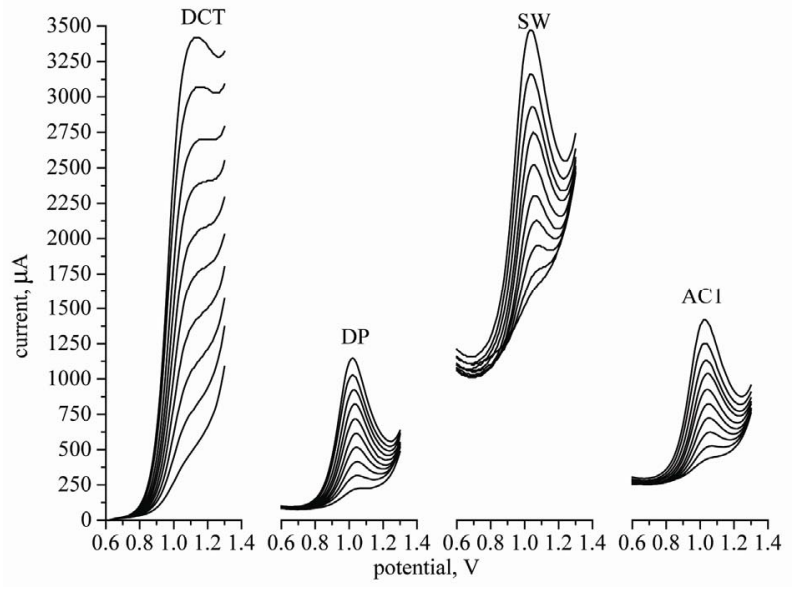

Figure 4. Different modes of sweeps, DCT, DP, SW and AC1, at different concentrations of nitrite $(0.41-2.46 \mathrm{ug} / \mathrm{ml}$ $\mathrm{NO}_{2}$ ) using $10 \%$ chitosan carbon paste electrode with scan rate $60 \mathrm{mV} / \mathrm{s}$, pulse amplitude $50 \mathrm{mV}$ in $0.1 \mathrm{M} \mathrm{KCl}$.

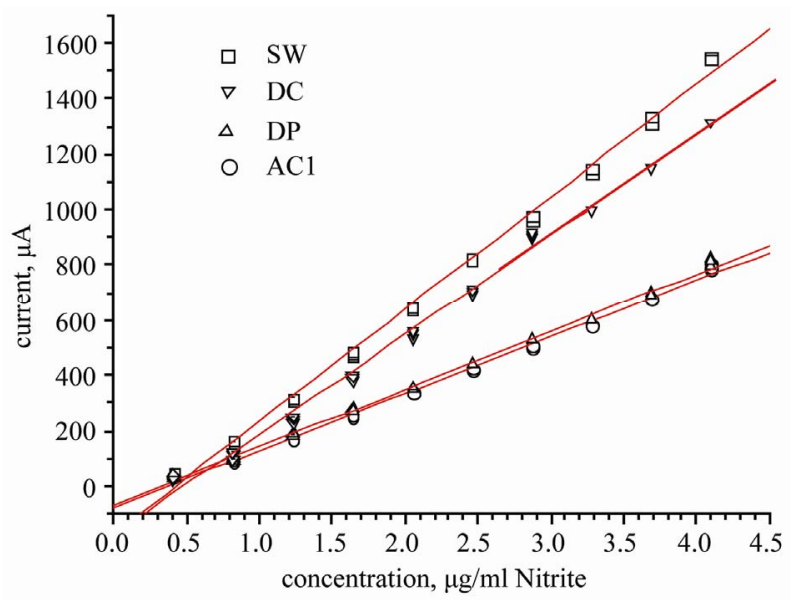

Figure 5. Regression lines for determining nitrite using different modes of sweep.

Table 1. Analytical parameters for nitrite determination at chitosan modified CP electrode.

\begin{tabular}{llcccl}
\hline Mode & $\mathrm{R}$ & $\begin{array}{c}\text { Slope, } \\
\mathrm{nA} / \mu \mathrm{g}\end{array}$ & $\begin{array}{l}\text { Intercepte } \\
\mathrm{nA} / \mu \mathrm{g}\end{array}$ & LOD $\mu \mathrm{g}$ & $\begin{array}{l}\text { Repeatability } \\
\text { RSD, \% }\end{array}$ \\
\hline $\mathrm{AC} 1$ & 0.998 & 204.78 & -74.76 & 0.241 & 0.668 \\
$\mathrm{DP}$ & 0.999 & 208.35 & -66.17 & 0.187 & 0.285 \\
$\mathrm{DC}$ & 0.994 & 360.86 & -173.00 & 0.281 & 1.018 \\
$\mathrm{SW}$ & 0.998 & 404.86 & -169.084 & 0.206 & 0.437 \\
\hline
\end{tabular}

An extremely attractive feature of the chitosan modified carbon paste electrode is its highly stable response toward nitrite oxidation. Repeatability "RSD" using different mode is found to be $1.018 \%, 0.285 \%, 0.437 \%$ and $0.668 \%$, respectively, for five successive determination of $2.46 \mu \mathrm{g} / \mathrm{ml}$ nitrite. For the same modified chitosan 
electrode, reproducibility, without and with successive cut off/polishing five times, is found to be $0.285 \%$ and $0.347 \%$, respectively, for $2.46 \mu \mathrm{g} / \mathrm{ml}$ nitrite and using DP mode.

It is concluded that the new and simple carbon paste electrode modified with chitosan has been shown to offer comparable performance to the more expensive glassy carbon or diamond electrodes for the practical use to analysis $\mathrm{NO}_{2}^{-}$ions at trace concentrations in real samples by anodic striping voltammetry with high sensitivity and selectivity.

\section{Acknowledgements}

Thanks are due to Volkswagen Stiftung, Kastanienallee 35, 30519 Hannover, Germany, for the financial support of purchasing the Metrohm model 693 VA processor and 694 VA stand.

\section{References}

[1] P. F. Swann, "The Toxicology of Nitrate, Nitrite and N-nitroso Compounds," Journal of Agricultural and Food Chemistry, Vol. 26, No. 1, January 1975, pp. 17611970. doi:10.1002/jsfa. 2740261119

[2] S. S. Mirvish, "Role of $N$-nitroso Compounds (NOC) and $\mathrm{N}$-Nitrosation in Etiology of Gastric, Esophageal, Nasopharyngeal and Bladder Cancer and Contribution to Cancer of Known Exposures to NOC," Cancer Letters, Vol. 93, No. 1, June 1995, pp. 17-48. doi:10.1016/0304-3835(95)03786-V

[3] P. Sharma and R. Sharma, "Sequential Trace Determination of Nitrate and Nitrite in Natural Waters by Differential Pulse Polarography," International Journal of Environmental Analytical Chemistry, Vol. 82, No. 1, 2002, pp. 7-11. doi:10.1080/03067310290024049

[4] H. Walter and J. J. Specchio, "Determination of Nitrite and Nitrate by Differential Pulse Polarography with Simultaneous Nitrogen Purging," Analytical Chemistry, Vol. 64, No. 11, 1992, pp. 1313-1322.

doi: $10.1021 / \mathrm{ac} 00035 \mathrm{a} 021$

[5] T. S. Sadallah and A. A. Banan, "Differential-Pulse Polarographic Determination of Nitrite," Analyst, Vol. 109, No. 12, 1984, pp. 1545-1547. doi:10.1039/an9840901545

[6] Y. P. Cui, C. Z. Yang, W. Zeng, M. Oyama, W. H. Pu and J. D. Zhang, "Electrochemical Determination of Nitrite Using a Gold Nanoparticles-Modified Glassy Carbon Electrode Prepared by the Seed-Mediated Growth Technique," Analytical Science, Vol. 23, No. 12, 2007, pp. 1421-1425. doi:10.2116/analsci.23.1421

[7] Ü. T. Yilmaz and G. Somer, "Determination of Trace Nitrite by Direct and Indirect Methods Using Differential Pulse Polarography and Application," Journal of Electroanalytical Chemistry, Vol. 624, No. 1-2, 2008, pp. 59-63. doi:10.1016/j.jelechem.2008.07.025
[8] J. R. Caetano da Rocha, L. Angnes, M. Bertotti, K. Araki and H. E. Toma, "Amperometric Detection of Nitrite and Nitrate at Tetraruthenated Porphyrin-Modified Electrodes in a Continuous-Flow Assembly," Analytica Chimica Acta, Vol. 452, No. 1, January 2002, pp. 23-28. doi:10.1016/S0003-2670(01)01440-4

[9] A. Salimi, A. Noorbakhash and F. S. Karonian, "Amperometric Detection of Nitrite, Iodate and Periodate on Glassy Carbon Electrode Modified with Thionin and Multi-Wall Carbon Nanotubes," International Journal of Electrochemcal Science, Vol. 1, No. 9 , 2006, pp. 435-446

[10] L. Guanghan, J. Hong and S. Dandan, "Determination of Trace Nitrite by Anodic Stripping Voltammetry," Food Chemistry, Vol. 59, No. 4, 1997, pp. 583-587. doi:10.1016/S0308-8146(96)00290-7

[11] J. Markus and M. Fedurco, "Vitamin $\mathrm{B}_{12}$ as Coordinating Agent for the Voltammetric Determination of Nitrite in Natural Waters," Analytica Chimica Acta, Vol. 248, No. 1, July 1991, pp. 109-115. doi:10.1016/S0003-2670(00)80875-2

[12] S. M. Silva and L. H. Mazo, "Differential Pulse Voltammetric Determination of Nitrite with Gold Ultramicroelectrode," Electroanalysis, Vol. 10, No. 17, 1998, pp. 1200-1203.

doi:10.1002/(SICI)1521-4109(199811)10:17<1200::AID$\underline{\text { ELAN1200>3.0.CO;2-5 }}$

[13] C. M. G. Van den Berg and H. Li, "Potentiometric and Voltammetric Responses of Carbon Fibre Electrodes," Analytica Chimica Acta, Vol. 212, 1988, pp. 31-41. doi:10.1016/S0003-2670(00)84126-4

[14] M. Badea, A. Amine, M. Benzine, A. Curulli, D. Moscone, A. Lupu, G. Volpe and G. Palleschi, "Rapid and Selective Electrochemical Determination of Nitrite in Cured Meat in the Presence of Ascorbic Acid," Microchimica Acta, Vol. 147, No. 1-2, 2004, pp. 51-58. doi:10.1007/s00604-004-0220-8

[15] J. E. Toth and F. C. Anson, "Electrocatalytic Reducetion of Nitrite and Nitric Oxide to Ammonia with Iron-Substituted Polyoxotungstates," Journal of the American Chemical Society, Vol. 111, No. 7, March 1989, pp. 2444-2451. doi:10.1021/ja00189a012

[16] W. J. R. Santos, Ph. R. Lima, A. A. Tanaka, S. M. C. N. Tanaka and L. T. Kubota, "Determination of Nitrite in Food Samples by Anodic Voltammetry Using a Modified Electrode," Food Chemistry, Vol. 113, No. 4, 2009, pp. 1206-1211. doi:10.1016/j.foodchem.2008.08.009

[17] W. Sun, S. Zhang, H. Liu, L. Jin and J. Kong, "Electrocatalytic Reduction of Nitrite at a Glassy Carbon Electrode Surface Modified with Palladium (II)-Substituted Keggin Type Heteropolytungstate," Analytica Chimica Acta, Vol. 388, No. 1-2, May 1999, pp. 103-110. doi:10.1016/S0003-2670(99)00064-1

[18] W. Sun, F. Yang, H. Liu, L. Jin, J. Kong, S. Jin, G. Xie and J. Deng, "Electrochemical and Electrocatalytic Properties of Iridium(IV)-Substituted Dawson Type Polyoxotungstate," Journal of Electroanalytical Chemistry, Vol. 451, No. 1-2, July 1998, pp. 49-57. doi:10.1016/S0022-0728(97)00511-1 
[19] M. Thamae and T. Nyokog, "Cobalt (II) Porphyrazine Catalysed Reduction of Nitrite," Journal of Electroanalytical Chemistry, Vol. 470, No. 2, July 1999, pp. 126135. doi:10.1016/S0022-0728(99)00224-7

[20] C. S. Fung and K. Y. Wong, "Electrocatalytic Reduction of Nitrite by Copper Complexes of 1, 10-Phenanthroline and 2,2':6',2"-Terpyridine," Journal of Electroanalytical Chemistry, Vol. 401, No. 1-2, January 1996, pp. 263-268. doi:10.1016/0022-0728(95)04414-0

[21] L. Ruhlmann and G. Genet, "Wells-Dawson-derived Tetrameric Complexes $\left\{\mathrm{K}_{28} \mathrm{H}_{8}\left[\mathrm{P}_{2} \mathrm{~W}_{15} \mathrm{Ti}_{3} \mathrm{O}_{60.5}\right]_{4}\right\}$ Electrochemical Behaviour and Electrocatalytic Reducetion of Nitrite and of Nitric Oxide," Journal of Electroanalytical Chemistry, Vol. 568, July 2004, pp. 315-321. doi:10.1016/j.jelechem.2004.02.020

[22] S. Liu, Z. Shi and S. Dong, "Preparation of a Composite Film Electrode Containing 12-Tungstosilicic Acid and Its Electrocatalytic Reduction for Nitrite," Electroanalysis, Vol. 10, No. 13, 1998, pp. 891-896.

[23] S. Dong, X. Xi and M. Tian, "Study of the Electrocatalytic Reduction of Nitrite with Silicotungstic Heteropolyanion," Journal of Electroanalytical Chemistry, Vol. 385, No. 2, 1995, pp. 227-233. doi:10.1016/0022-0728(94)03770-4

[24] L. Cheng and S. Dong, "Electrochemical Behavior and Electrocatalytic Properties of Ultrathin Films Containing Silicotungstic Heteropolyanion $\mathrm{SiW}_{12} \mathrm{O}_{40}{ }^{4-}$, Journal of the Electrochemical Society, Vol. 147, No. 2, 2000, pp. 606-612. doi:10.1149/1.1393241

[25] X. Wang, E. Wang and C. Hu, "Hybrid Inorganic- Organic Material Containing 12-Molybdophosphate Bulk-Modified Carbon Paste Electrode," Chemistry Letters, Vol. 30, No. 10, 2001, pp. 1030-1031. doi:10.1246/cl.2001.1030

[26] N. Spataru, T. N. Rao, D. A. Tryk and A. Fujishima, "Determination of Nitrite and Nitrogen Oxides by Anodic Voltammetry at Conductive Diamond Electrodes," Journal of Electrochemical Society, Vol. 148, No. 3, 2001, pp. E112-E117.

[27] A. J. Varma, S. V. Deshpande and J. F. Kennedy; "Metal Complexation by Chitosan and its Derivatives: A Review," Carbohydrate Polymers, Vol. 55, No. 1, January
2004, pp. 77-93. doi:10.1016/j.carbpol.2003.08.005

[28] E. Guibal; "Interactions of Metal Ions with ChitosanBased Sorbents: A Review," Separation and Purification Technology, Vol. 38, No. 1, July 2004, pp. 43-74.

[29] Q. H. Yang, X. Z. Ye and Z. C. Hong, "LihuaJianyan, Huaxue-Fence," Analytical Abstracts, Vol. 36, No. 161, 2000.

[30] X. Z. Ye, Q. H. Yang; Y. Wang and N. Q. Li, "Electrochemical Behaviour of Gold, Silver, Platinum and Palladium on the Glassy Carbon Electrode Modified by Chitosan and its Application," Talanta, Vol. 47, No. 5, December 1998, pp. 1099-1106. doi:10.1016/S0039-9140(98)00189-1

[31] Q. H. Yang, X. Z. Ye and H. Wang, "Fenxi-Shi-yanshi," Analytical Abstracts, Vol. 17, 1998, p. 5.

[32] R. A. Y. Hassan, I. H. I. Habib and H. N. A. Hassan, "Voltammetric Determination of Lead (II) in Medical Lotion and Biological Samples Using Chitosan-Carbon Paste Electrode," International Journal of Electrochemcal Science, Vol. 3, No. 8, 2008, pp. 935-945.

[33] J. R. Xu and B. Liu, "Preconcentration and Determination of Lead Ions at a Chitosan-Modified Glassy Carbon Electrode," Analyst, Vol. 119, No. 7, 1994, pp. 1599-1601. doi:10.1039/an9941901599

[34] G. H. Lu, X. Yao, X. G. Wu and T. Zhan, "Determination of the Total Iron by Chitosan-Modified Glassy Carbon Electrode," Microchemical Journal, Vol. 69, No. 1, May 2001, pp. 81-87. doi:10.1016/S0026-265X(01)00066-2

[35] J. A. Cox and P. J. Kulesza, "Oxidation and Determination of Nitrite at Modified Electrodes," Journal of Electroanalytical Chemistry, Vol. 175, No. 1-2, September 1984, pp. 105-118. doi:10.1016/S0022-0728(84)80349-6

[36] R. B. Almeida, S. S. S. Borges and M. G. Gomes, "Determination of Nitrite in Aqueous Solutions Using the Linear Sweep Voltammetry Technique," Analytical Letters, Vol. 32, No. 6, 1999, pp. 1203-1210. doi:10.1080/00032719908542889

[37] J. C. Miller and J. N. Miller, "Statistics for Analytical Chemistry," 2nd Edition, 1988, Ellis Horwood Ltd., Chichester, p. 115. 